Murata K., Tezel A., Koskela L., and Tzortzopoulos P. (2017). “An Application of Control Theory to Visual Management for Organizational Communication in Construction” In: LC3 2017 Volume II - Proceedings of the 25th Annual Conference of the International Group for Lean Construction (IGLC), Walsh, K., Sacks, R., Brilakis, I. (eds.), Heraklion, Greece, pp.185-191. DOI: https://doi.org/10.24928/2017/0346

\title{
AN APPLICATION OF CONTROL THEORY TO VISUAL MANAGEMENT FOR ORGANIZATIONAL COMMUNICATION IN CONSTRUCTION
}

\author{
Koichi Murata ${ }^{1}$, Algan Tezel ${ }^{2}$, Lauri Koskela ${ }^{3}$, and Patricia Tzortzopoulos ${ }^{4}$
}

\begin{abstract}
Insufficient process transparency is one of the main reasons for process waste, quality deviations and safety non-conformances in construction. Lean Production frequently resorts to a range of visual communication strategies called Visual Management (VM) to increase the level of process transparency and to support continuous improvement at the workplace. Although VM is a fundamental part of the Lean toolbox, theoretical or empirical studies on the role of VM in team activities are scarce. This study explores VM in construction through a block diagram used in control theory. Two VM tools for construction teams from construction companies in the UK and Japan are analysed in detail. The initial findings suggest that VM can and must cover various communication levels in construction organizations in order to break the barriers for information flows and to share valuable and newest knowledge.
\end{abstract}

Keywords: Lean construction, Visual management, Communication, Control theory.

\section{INTRODUCTION}

Despite the rapid advent of digital visualization technologies in construction, conventional visual tools, an information board or an idea generation post-it, have also been utilized to cover the functions which the IT-based visualization cannot effectively present. This type of conventional visual tools are often utilized to improve process transparency. There are many studies on the role of conventional VM in factory management in the manufacturing industry (Greif 1991, Mestre 2000). Although similar research for the construction industry (Murata 2015, Tezel 2015 and Tjell 2015) has recently increased in the context of lean construction, there is a need for further understanding of VM in construction to help constitute a VM theory and to guide construction practitioners who design and install VM tools in their work environments. Based on this recognition, this paper aims at the introduction of a generic theoretical approach to VM as well as at the demonstration of its application to construction.

The paper is structured as follows. The following section presents the adopted theoretical and methodological approach to VM. Next, the characteristics of communication in the construction industry are analyzed, and based on this analysis and

Associate Professor, College of Industrial Technology, Nihon University, Chiba, JAPAN, murata.kouichi30@nihon-u.ac.jp

2 Researcher, School of Art, Design and Architecture, University of Huddersfield, Huddersfield, UK, A.Tezel@hud.ac.uk

3 Professor of Construction and Project Management, University of Huddersfield, Huddersfield, UK, L.Koskela@hud.ac.uk

4 Professor, School of Art, Design and Architecture, University of Huddersfield, Huddersfield, UK, P.Tzortzopoulos@hud.ac.uk 
the theoretical model of VM, two construction VM tools are examined. A discussion of findings and concluding remarks complete the paper.

\section{THEORETICAL AND METHODOLOGICAL APPROACH}

In the study, a graphical block diagram from control theory (Davis 1993) is applied to explore a VM system. The method has been widely known in mechanical engineering, inventory management, and supply chain management. As part of the theory development, a conceptual approach to $\mathrm{VM}$ and a number of generic requirements to VM tool design are presented in the following.

Let us describe a VM system through the mentioned method (Figure 1). The optimum performance $\theta_{\mathrm{I}}$ is the input data, the actual performance $\theta_{\mathrm{O}}$ is the output data and the difference between these two data $\varepsilon\left(=\theta_{\mathrm{I}}-\theta_{\mathrm{O}}\right)$ is an error. Variations in management resources $\theta_{\mathrm{R}}$ (workers, materials, machines, etc.) create disturbances to the production system $K_{1}$ as a controlled object. The VM system $K_{2}$ determines a manipulated variable $\mu$ to minimize the difference $\varepsilon$. The variable $\mu$ is an input to the production system $K_{1}$.

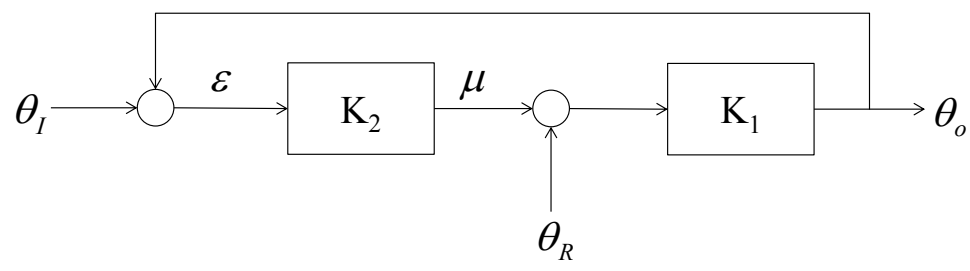

Figure 1: A production system $\left(\mathrm{K}_{1}\right)$ with a VM system $\left(\mathrm{K}_{2}\right)$.

The analytical method used in this paper is demonstrated in Figure 2. It shows the inside of the VM system $\mathrm{K}_{2}$ in Figure 1. Within the framework, VM systems are thought of as tools that support communication between humans and the production systems that are managed by humans. The framework has three components: a) humans as a receiver of error information $\alpha$ and an executor of $\mu, b)$ the production system $K_{1}$ managed by humans, and c) a tool to realize VM. This framework aims to represent two key items: 1) a reaction $\mu$ requested by the production system from the humans, and 2) functions of the tool.

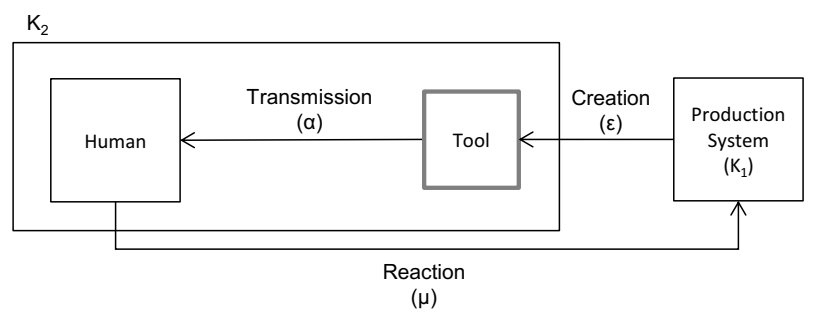

Figure 2: The basic mechanism of a VM system (Murata 2016)

The reaction $\mu$ is a human action requested by the production system when it fails. When designing a reaction, its comprehensibility and the level of expertise/experience of the human, of which the relationship seems to be a trade-off, as presented in Figure 3, need to be considered thoroughly. 


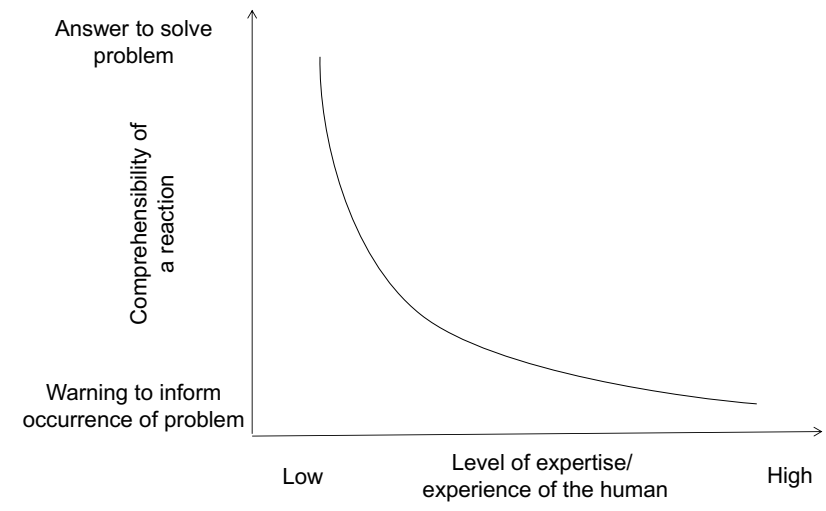

Figure 3: Relationship between expertise/ experience level and indicated information level

For the second item, two tool functions, namely creation of information $\varepsilon$ and transmission of information $\alpha$, need to be designed. In the first function, a visualized item created by the production system is designed and sent from the system to a tool. When designing this function, the non-ordinariness and continuity of the created information need to be considered. The non-ordinariness needs to be designed to notice when a visualized item needs to be created. When the production system is in the ordinary condition, the tool is not required to work. This tool's important role is to handle a special situation within a production system. With regard to continuity, the tool must have a structure to monitor the typical conditions of the production system in order to grasp special situations at any time as they arise. In the second function, the visualized and created items are provided from the tool to a manager or an operator. When designing this function, the inducibility and immediacy of the delivered visualized item need to be considered. With regard to the former, the tool needs to have appeal for operators because their physical and mental condition may not always be stable. In order to improve the capability of inducibility in the tool, it is necessary to build a device that attracts the operator's attention to the tool. With regard to the latter, the timing of delivery of the created visualized item has to be when an immediate reaction is required to the prevailing condition of the production system.

Two VM systems, from the UK and Japan, are analysed using the following three research questions related to the model shown in Figure 2.

1. What are the three components?

2. What do the managed system require of you when it fails?

3. How do you visualize?

- What do you visualize?

- How do you design a device to attract attention?

\section{ANALYSIS OF VM SYSTEMS}

\subsection{Nested Communications in Construction Industry}

Construction projects are executed at the same time and in different locations. Many different specialists join one project according to the plan progressing by turns. While the former causes a geographical boundary, the latter draws out a temporal boundary for communication. This two-boundary structure has other structures nesting inside it. Each 
structure involves each worksite of each project at present. The characteristics of communication in the construction industry is shown in Figure 4.

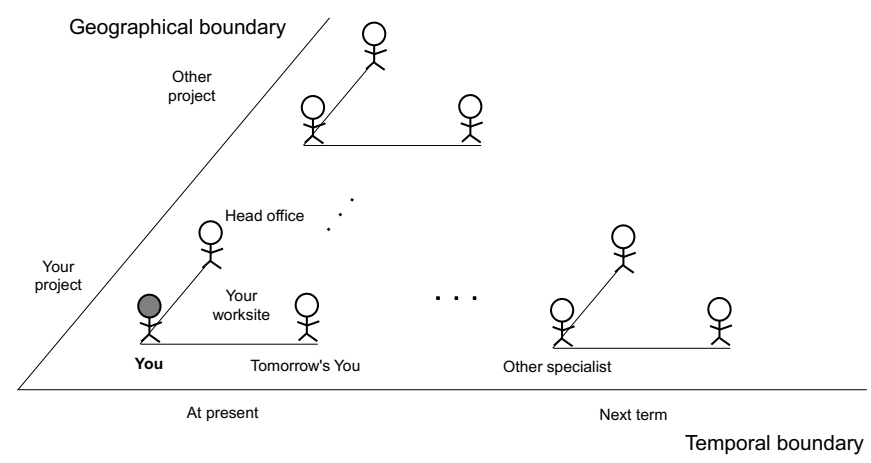

Figure 4: Nested structure model of communications in the construction industry

Two analysed VM tools shown in Figure 5 are 1) a daily communication tool among project members and 2) a report method at one company for the worksite, local office and the head office. The first investigated object, which is used to break a temporal boundary for communication, is from a major improvement project in England's strategic highways network. The second object, which is used to break a geographical boundary for communication, is from an information sharing system used in a construction company located in Japan.

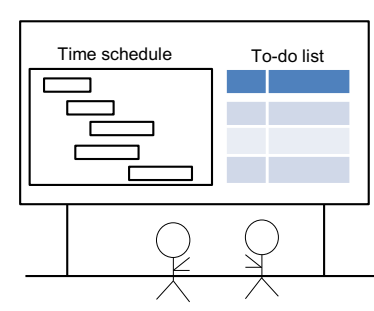

System 1

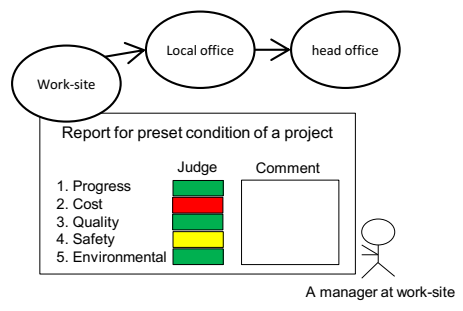

System 2

Figure 5: Schematic illustration of the two VM systems

\subsection{The first VM System}

A progress chart is used as an important tool for daily communication, in order to draw the plan of a project, to ascertain whether it has progressed as scheduled or not, and to re-schedule it, if it is late. The UK company have been using some progress charts, and it was found by observation that their design procedure consists of three selection steps explained as follows.

The first selection is how to make a progress chart as the base to comprehensively manage a project on a worksite. One option is an object drawn directly on a whiteboard. The other option is an object printed from a scheduling software. The initial design of the former and its continuous customization are definitely laxer than the latter, of which the format is fixed but which is easy to print.

The second selection is a time schedule like a Gantt chart or with the diagram of a structure plan. Regarding both alternatives, the length of a term of a project indicated in a time chart needs to be decided, for instance, one day, one week or two weeks and so on. In some cases, time charts are also used with strings in the case company. The length and the slope of each string express the length of one process and the degree of its progress. Colourful magnets are also put to represent construction machines and 
materials on the board. The latter will be better in a case that a finished product is difficult to imagine because of the phased progress of processes in a long-term project.

A whiteboard for a To-do list is added next to a progress chart in the third selection. The discussion of prompt action with the direct-writing onto the To-do list is considered as efficient management with a process chart. The addition of an application rule of the whiteboard is necessary to continuously prevent the emasculation of it. Coloured post-it notes and/or colourful marker pens are also useful to promote problem-solving.

\subsection{The second VM System}

Construction projects in the case company in Japan are managed by three actors; managers at the work-site, local offices, and head office. The managers at the work-sites actually execute the construction projects. They must report the project progress to the local offices, to which each of them belongs, every month.

In this report, they describe the present condition of their projects from six viewpoints: plan progress, cost, quality, safety, environment, and others. They also evaluate each item with three colours: green, yellow, and red, similarly to the andon, the Japanese word for a stack light with several colours to support just-in-time operation. Green means that the project performance is on track. Yellow means that the project is susceptible to problems (problems are expected). Red means that the project has problems in the corresponding measurement parameter. The local offices evaluate the present condition of a project coming in through the report and send it to the head office. The head office performs a final evaluation and decides on a support level, which consists of three levels. The first level (green) designates keeping watch on a project. The second level (yellow) requires support from an expert on a problem that needs to be solved. The third level (red) requires support from a team of experts on a problem that needs to be solved. The execution of the performance reporting is similar to the andon system.

\section{DISCUSSION}

The comparison of the analysed results of the two tools are summarized in Figures 6 and 7.

As for the analysis of the first tool, the type of the production system is a worksite $\left(\mathrm{K}_{1}\right)$. The human attribute is project members. The VM system is a progress chart used as a daily communication tool $\left(\mathrm{K}_{2}\right)$. The reaction $(\mu)$ from the project members to the worksite is designed to deliver quick and adequate actions for the project at the worksite level. The design of the two functions to create information $(\varepsilon)$ and transit of the created information $(\alpha)$ performs in the three selections described in Section 3.2. The items visualized in the former function are the progress of a project, the length of the term of a project, the diagram of a structure plan, machines, materials, and a To-do list. The base to transit the visualised items in the latter function is an object drawn directly on the whiteboard or an object printed from a scheduling software. There are many visual artefacts such as a time chart, the diagram, a drawing, a picture, a photograph, a string, colourful magnets, colourful post-it notes, colourful marker pens, and a direct-writing on the base. 


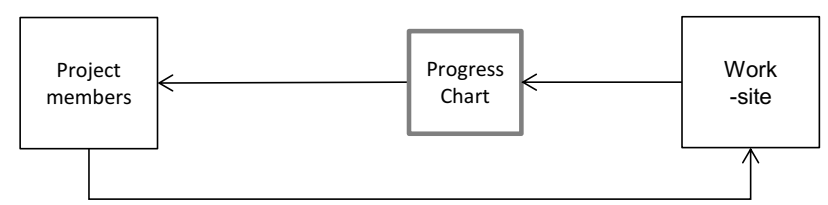

Figure 6: Conceptual diagram of the first VM system

As for the analysed result of the second tool, the type of system is a worksite $\left(\mathrm{K}_{1}\right)$. The human attribute is both a local office and a head office. The VM system is a report of the present condition of the project $\left(\mathrm{K}_{2}\right)$. The reaction $(\mu)$ from the local office and a head office to the worksite is designed to deliver quick and adequate support for the project. For the 'how to create information' $(\varepsilon)$, the work site describes the present condition of a project from the aforementioned six perspectives every month and evaluates each item using three colours. For 'how to transmit information' $(\alpha)$, the local office and a head office evaluate the judgment of the present condition of the project by the work-site and decide support levels based on this evaluation.

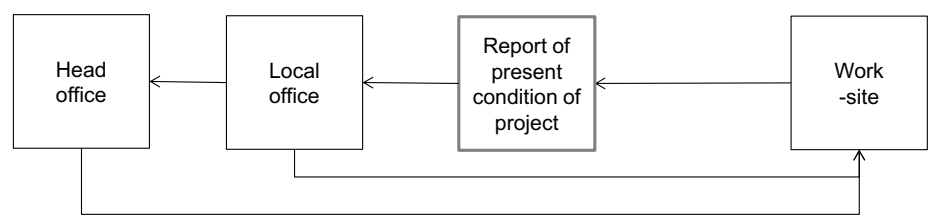

Figure 7: Conceptual diagram of the second VM system

\section{CONCLUDING REMARKS}

The paper delivers three contributions in relation to VM in construction. First, a generic conceptual approach to VM is provided, along with a discussion on design criteria of VM tools. Second, the characteristics of a communication model for the construction industry are proposed. The design of a VM system for smooth information sharing must start with considering this complicated and obstructive structure. The third is the description of the roles and functions of two VM tools to overcome the boundaries in the proposed communication model. The analysis of the two systems revealed the roles and functions of VM; (1) a managed system, (2) an attribute of a receiver of a visualised item, and (3) an action requested by a managed system from the receiver as the roles, and creating and transmitting the visualised item as the functions. The analysis demonstrates that the generic conceptual approach to VM can be used also in construction.

The initial finding of the research is that VM can and must cover various communication levels in construction organizations in order to break the barriers before information flows and to share valuable and newest information. As the collection of VM tools corresponding to all the boundaries indicated in the communication model is not complete, the study needs to continue in the future using the same VM analysis logic. Furthermore, it is important to launch an evaluative analysis of existing VM tools in construction, based on the generic requirements identified, and proceed towards a prescription in terms of practical design criteria for VM tools. Additional research is also necessary to compare and contrast the realization of VM in different countries through an international survey project. 


\section{REFERENCES}

Davis, T. (1993). Effective supply chain management. Sloan management review, 34(4), pp. 35-46.

Greif, M. (1991). The visual factory: building participation through shared information. CRC Press, Boca Raton, FL.

Mestre, M., Stainer, A., Stainer, L., and Strom, B. (2000). Visual Communications -the Japanese Experience. Corporate Communications: An International Journal, 5(1), pp. 34-41.

Murata, K. (2016). A Case Study for Knowledge Sharing of Kaizen Activity in Construction Industry. In Proceedings of 46th International Conference on Computers \& Industrial Engineering (CIE46), 8 pages, Tianjin University, Tianjin, China, 29th -31th October, 2016.

Murata, K., Nakajima, K., Kinoshita, K., Tezel, A., Koskela, L., Tzortzopoulos, P., and Katayama, H. (2015). Investigation of Visual Management Cases in Construction by an Analytical Framework from Manufacturing. In Proceedings of 45th International Conference on Computers \& Industrial Engineering (CIE45), pp. 744-751, Université de Lorraine, Metz, France.

Tezel, A., Koskela, L., Tzortzopoulos, P., Formoso, C. T., and Alves, T. (2015). Visual Management in Brazilian Construction Companies: Taxonomy and Guidelines for Implementation. Journal of Management in Engineering, 31(6), 05015001.

Tjell, J., and Bosch-Sijtsema, P. M. (2015). Visual Management in Mid-sized Construction Design Projects. Procedia Economics and Finance, 21, pp. 193-200, Boston, MA, USA. 